\title{
A research into the Application of Machine Translation in the Translation Teaching
}

\author{
Jin Liu \\ Wuhan Polytechnic University, College of Foreign Languages, Wuhan, China \\ 208962582@email.com
}

Keywords: Machine Translation; Translation Teaching; Cognition of the Translation.

\begin{abstract}
This paper aims to discuss the advantages and disadvantages of machine translation, explore the teaching methods based on the application of machine translation. It will give a teaching case to explain how essential for a teacher to grasp the machine translation as a tool. The paper will compare the translations between machine translation and students' translation under different translation skills in order to train student's translation ability. After the teaching experiment, 30 students will be involved in this survey. It comes to the conclusion that machine translation teaching can improve students' cognition of the bilingual structure and enhance students' recognition of the deep culture difference between two languages.
\end{abstract}

\section{Introduction}

With the increasing development of technology, machine translation has become one of the heated topics of natural human language. In 1949, Warren. Weaver is the first person who put forward the notion "machine translation" in his article "Translation". From then on, a large number of researches about machine translation were emerged up from about 1950s to 1960s.however, after a blooming progress, machine translation researches were followed by criticism report(ALPAC) , which delivered by national Academy of sciences, as a result of the machine translation's develop to a stagnation. From the late 1960s to the whole 1970s, the development of machine translation walked at a stable. There is a resurgence of machine translation research from 1980s, in terms of the quick development of the Computer Science and Linguistic research. Because of its convenient and practical, large numbers of text were translated by machine from 1990s, and what pleased us is the continuing and increasing of the machine translation research. Although machine translation research was on a way of hard and long, we can hold the view that machine translation still has a challenge and prospect way to go.

In this research, we aim at an integrated study of the machine software construction. Then, the paper will give an analysis to the existed research about machine translation and translation teaching and it will demonstrate the teaching process. Specifically, we shall describe the problems of the machine translation from the syntactic, semantic and context perspective within the Systemic Functional Linguistics framework by citing examples from a corpus. Then we try to probe into the problem of how translation software works such as, how to build a corpus of analysis system based on the bi-lingual or specific context in the machine translation software to help the translation teaching.

In 2005, the office of "Halliday Center for Intelligent Applications of Language Studies, HCLS" was established in the City University of HongKong. M.A.K. Halliday gave an inaugurate speech "Working with Meaning, towards An Applicable Linguistics" on 26th, March, 2006.(Gibb, Zhiyou Zheng,2006). HU Zhuang-lin published an article “A Tentative Interpretation of M.A.K. Halliday's "Applicable Linguistics"”, according to HU Zhuang-lin's opinion, the topic of "Intelligent Applications" is the breakthrough of Applied Linguistics. And he also quoted Professor Jonathan Webster's three issues, one of the issues is about machine translation, to mention that M.A.K. Halliday's "social accountability" takes great efficient to the value of social.

The research proposal will be given some experimental results to show the current problems of 
the machine translation. It will discuss the method to solve the issues and try to create a translation model based on the systematic function linguistics. The paper makes a research into the total publishing number of the paper about "machine translation", it can be found that it become more and more hot in 2016.

Chart 1: the published trend

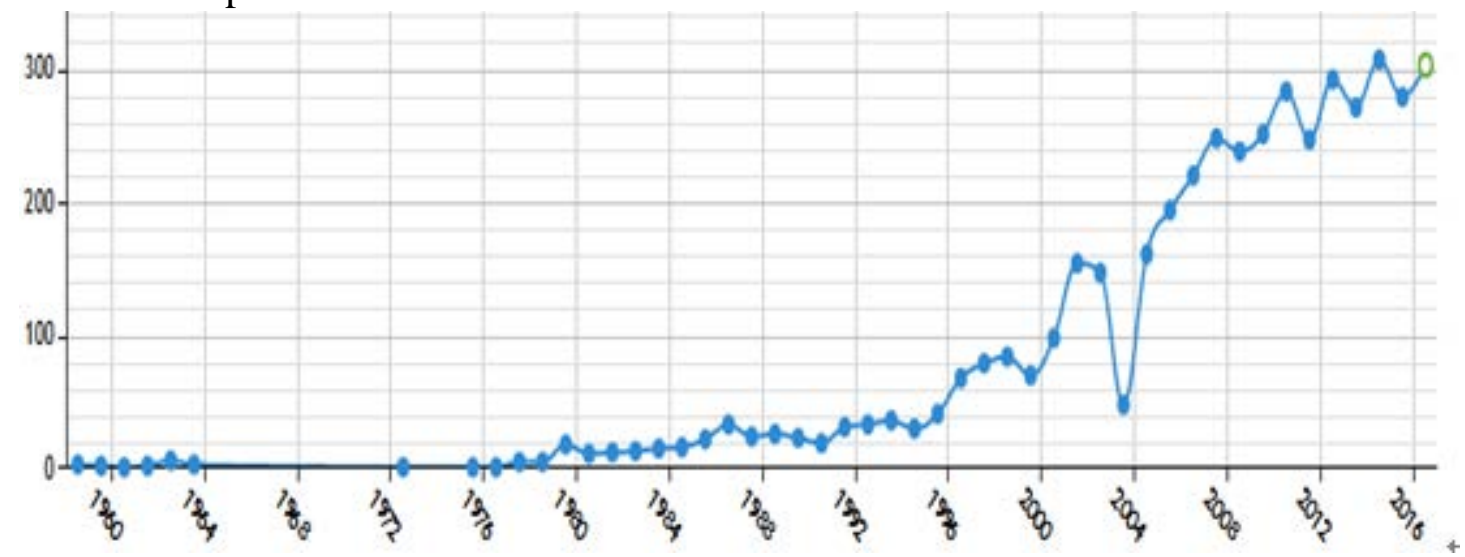

\section{Problem Statements}

The field of research in machine translation can generally be regarded as two categories: one is based on the rule research; the other is based on the corpus research. This thesis mainly will focus on the problems of the machine translation. Some empirical examples will be elected to find out the main problem. It is not only in need of the technology's creation, but also in need of the cognition of the language essence and computer language model. So, How to apply the machine translation to the translation teaching does counts.

The researches about "machine translation" and "translation teaching” present a rising trend in the publication as Chart 2.

Chart 2: the publication of the "machine translation" and "translation teaching"

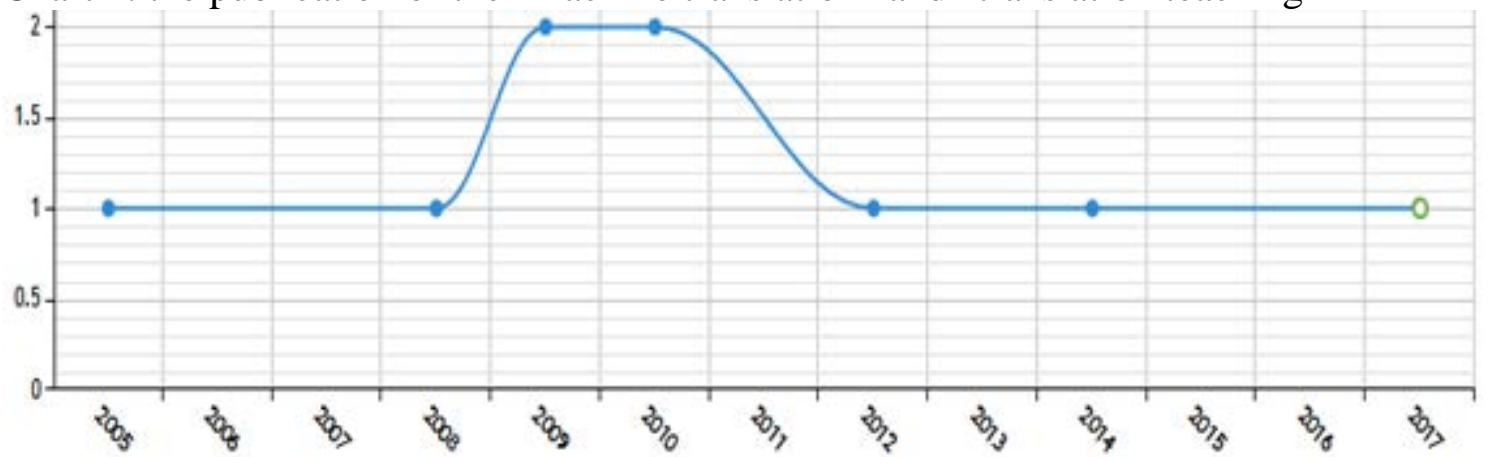

The paper just selected two commonly used machine translation software to compare their results and come to the problems. The research will present three categories of the errors.

1. Linguistic Problems of the deixis and meanings Translation

I heard the ladies talk horse.

【ICIBA】我听到那些女士们谈论马。

【Youdao】我听到了女士们谈论马。

[Students]我听到了那些女士谈论赛马的事情。我听到了那些女士们在吹牛。

The "horse "in western country usually was for race, so nearly all the vocabulary with "horse" may have some related meaning to the race. For this sentence, the two kinds of software can have a direct meaning but not with the cultural meaning. So is it eligible to create software that can have two different meaning for a sentence?

After the discussion, students realize that it is important to understand the cultural difference before the translation. They also grasp the literal translation skills. 


\section{Linguistic Problems of the Context Translation}

The cold never bothered him.

\section{【ICIBA】冷不打扰他}

【Youdao】寒冷的从未困扰着他

[Students] 他不怕冷

The two translation machines only can read the surface meaning rather than the context. After students' discuss, they understand the importance of the context translation. The machine translation cannot change the order. Know the difference of the English and Chinese's characteristics is essential for the students' translation.

3. Idioms

He is thick in the head.

【ICIBA】他是厚头。

【Youdao】他是厚的头。

[Students] 他很愚笨。

The disadvantage of the machine translation is obvious from the above example. the machine cannot read the American idioms. So, students should memorize some of the American idioms and grasp the large vocabulary. Some of the idioms like this cannot be translated correctly. Actually, we can build some idioms corpus or cultural vocabulary to the software.

4. Conversation

I'm sorry. It slipped my mind....

You will forget your own head one day....

【ICIBA】A:对不起。我忘了 ...

$\mathrm{B}$ :你会忘记你自己的头一天...

【Youdao】A：我很抱兼。我忘记了…。

$\mathrm{B}$ :你会忘记你自己的头一天...。

[Students]A：对不起, 我忘记了......

B: 你很健忘

We can collect thousands of examples like this to illustrate the problems. After the discussion, students know the negative translation skills to make the translation more clearly and fluently.

Most of the machine translation errors are regarded as the difference of the two languages' cultural, ideas, natural resources, social systems, and customs and so on.

The teacher applies the machine translation to the translation teaching and demonstrates different kinds of the translation problems to students, in order to help them form the cognition translation thought. Machine translation focus on the conversion of language, it cannot replace the human translation, so students should grasp the main translation skill.

\section{Teaching Methods}

The examples will be used in this research come from my self-built corpus, which contains much of the typical errors from the machine translation. At this first stage, the teacher collects the words or sentences from different cultural contexts to classify the errors from the machine translation between Chinese and English. The teacher will prepare different text types we come across, which include those from academic writings, news features, and novels to make comparison in the translation class.

The teacher can divide the students into several groups and ask them to find the differences between machine translation and translation teaching. The teacher can collect the machine translation's material to aid the translation teaching skills. 


\section{Conclusions}

The paper tries to illustrate the problems of the machine translation and intends to it will build a pragmatic and semantic corpus in the machine translation software in order to promote the context analysis of the machine translation. In that way, Machine translation can work as the human brain to give a cultural, context analysis to each sentence. Machine translation can give an innovation to translation teaching and also can perfect itself.

In a word, Machine translation plays an essential role in the process of translation teaching, it can stimulate students' cognition to the translation skills. The paper intends to give a reference to the future researches.

\section{Acknowledgement}

In this paper, the research was sponsored by the Foundation of Research Program of Wuhan Polytechnic University in 2018: A Research on Shapiro's Translation of “Red” Literature. The paper is regarded as one of the achievements of the program.

\section{References}

[1] Hutchins, W.John and Harold L. Somers. An introduction to Machine Translation [M]. London: Academic Press: 1992.

[2] Ball,R.V.”Computer-Aided Translation and the Modern Languages Curriculum”[J].The CTISS File 8,1989.52-55.

[3] Zhiwei Feng.Machine Translation:From Dream to Reality [J]. Chinese Translation Journals,1999(4):39-40.

[4] Wu Yun.The application of Computer-aid translation Technology system in the translation teaching $[\mathrm{J}]$.Audio-visual teaching of Foreign Language, 2006(6).

[5] Ke Ping. Machine Translation in Europe[J].Chinese Translation Journals, 1995, (2): 47-50. 